Abstracta Iranica

Revue bibliographique pour le domaine irano-aryen

Volume 32-33 | 2013

Comptes rendus des publications de 2009-2010

\title{
Maria Brosius. The Royal Audience Scene Reconsidered
}

\section{Rémy Boucharlat}

\section{(2) OpenEdition}

1 Journals

Édition électronique

URL : http://journals.openedition.org/abstractairanica/40214

DOI : 10.4000/abstractairanica.40214

ISSN : 1961-960X

\section{Éditeur :}

CNRS (UMR 7528 Mondes iraniens et indiens), Éditions de l'IFRI

\section{Édition imprimée}

Date de publication : 1 décembre 2013

ISSN : 0240-8910

\section{Référence électronique}

Rémy Boucharlat, «Maria Brosius. The Royal Audience Scene Reconsidered », Abstracta Iranica [En ligne], Volume 32-33 | 2013, document 44, mis en ligne le 01 juillet 2016, consulté le 26 septembre 2020. URL : http://journals.openedition.org/abstractairanica/40214; DOI : https://doi.org/10.4000/ abstractairanica.40214

Ce document a été généré automatiquement le 26 septembre 2020.

Tous droits réservés 


\title{
Maria Brosius. The Royal Audience Scene Reconsidered
}

\author{
Rémy Boucharlat
}

\section{RÉFÉRENCE}

Maria Brosius. «The Royal Audience Scene Reconsidered », in : J. Curtis and St J.

Simpson, eds., The world of Achaemenid Persia. History, Art and Society in Iran and the Ancient Near East. Proceedings of a Conference at the British Museum $29^{\text {th }}$ September $1^{\text {st }}$ October 2005. London, I.B. Tauris in partnership with Iran Heritage Foundation, 2010, p. 141-152.

1 Sous ce titre, l'A. revient sur la question de l'absence des représentations féminines sur les reliefs de Persépolis (comme ceux de Pasargades ou les panneaux de briques de Suse). En revanche, les figures de femme de haut rang sont bien attestées sur des basreliefs et plusieurs sceaux en Asie Mineure et en Égypte. La nouveauté réside dans la scène d'audience (?) d'une femme sur une impression de sceau d'une tablette de Persépolis. De style néo-élamite et portant une inscription également néo-élamite, la représentation évoque incontestablement les scènes d'audience royale des reliefs persépolitains. Elle est sans ambiguïté celle d'une femme de haut rang et non d'une divinité féminine. L'A. note que l'art et la culture élamites, dont on sait maintenant l'influence sur ceux des Achéménides, ont connu les représentations de femmes royales. 


\section{AUTEURS}

RÉMY BOUCHARLAT

CNRS, Lyon 